\title{
Canadian and US researchers swap ideas, bust myths
}

Cite as: CMAJ 2017 March 27;189:E476-7. doi: 10.1503/cmaj.1095404

W hen Canadian and US healthpolicy researchers gathered in Washington, DC, to swap ideas, the first order of business was to bust cross-border myths.

No, Canada's single-payer foundation does not mean equitable access, far from it. No, insured Americans can't always pick and choose their doctors or get swift treatment.

Which country offers a vast socialized health care program both run and paid for by the federal government? It's the US, with its cherished Medicare program for seniors that even President Donald Trump promises not to touch as he pushes to dismantle "Obamacare."

Researchers working in disparate health care environments found considerable common ground and shared headaches at the Mar. 2-3, 2017, symposium devoted to the advancement of integrated primary care in both countries. Dr. Robert Reid, chief scientist for Trillium Health Partners in Ontario, gave this as the bottom line for both populations on health care: "We pay a lot of money for it and don't really get the outcomes we deserve."

Americans heard of Canada's particular struggle to mount sustained innovation in integrated primary care financing and delivery, rather than pop-up experiments, and to stem the drain of primary care graduates drawn to more lucrative fields. Participants grappled with inequities in both countries, including the estimated $10 \%$ of Canadians and $18 \%$ of Americans who sometimes skip medication because they can't afford it.

"We've had several American commentators say, boy, I would continue to put Canadian health systems on pedestals, but a little lower," said Dr. Andrew Bazemore, director of the Robert Graham
Center, a health research organization in Washington. Indeed, researchers from both countries were unsparing in critiquing shortcomings in their own.

"The challenges ahead for Canada and the United States were amazingly similar," said Robyn Tamblyn, scientific director of the Institute of Health Services and Policy Research at the Canadian Institutes of Health Research, who helped organize the event.

A coming shakeup in US health policy, meanwhile, has researchers on edge on both sides of the border as Trump and his fellow Republicans controlling Congress move to repeal and replace the Affordable Care Act.
The 2010 overhaul, known as Obamacare, has helped drive an expansion of insurance to 20 million more Americans and achieved a record low in the rate of the uninsured (below 9\%). At the time of this writing, a detailed replacement plan has not emerged, but it's likely that the mandate for almost everyone to obtain health insurance will be dropped and doubtful that subsidies anchoring the expansion will be sustained at the same level.

The stakes are substantial for Canada and beyond because of the research money set loose by Obamacare. Will Trump squeeze medical and health-policy research to pay for his proposed military buildup and other big-ticket items?

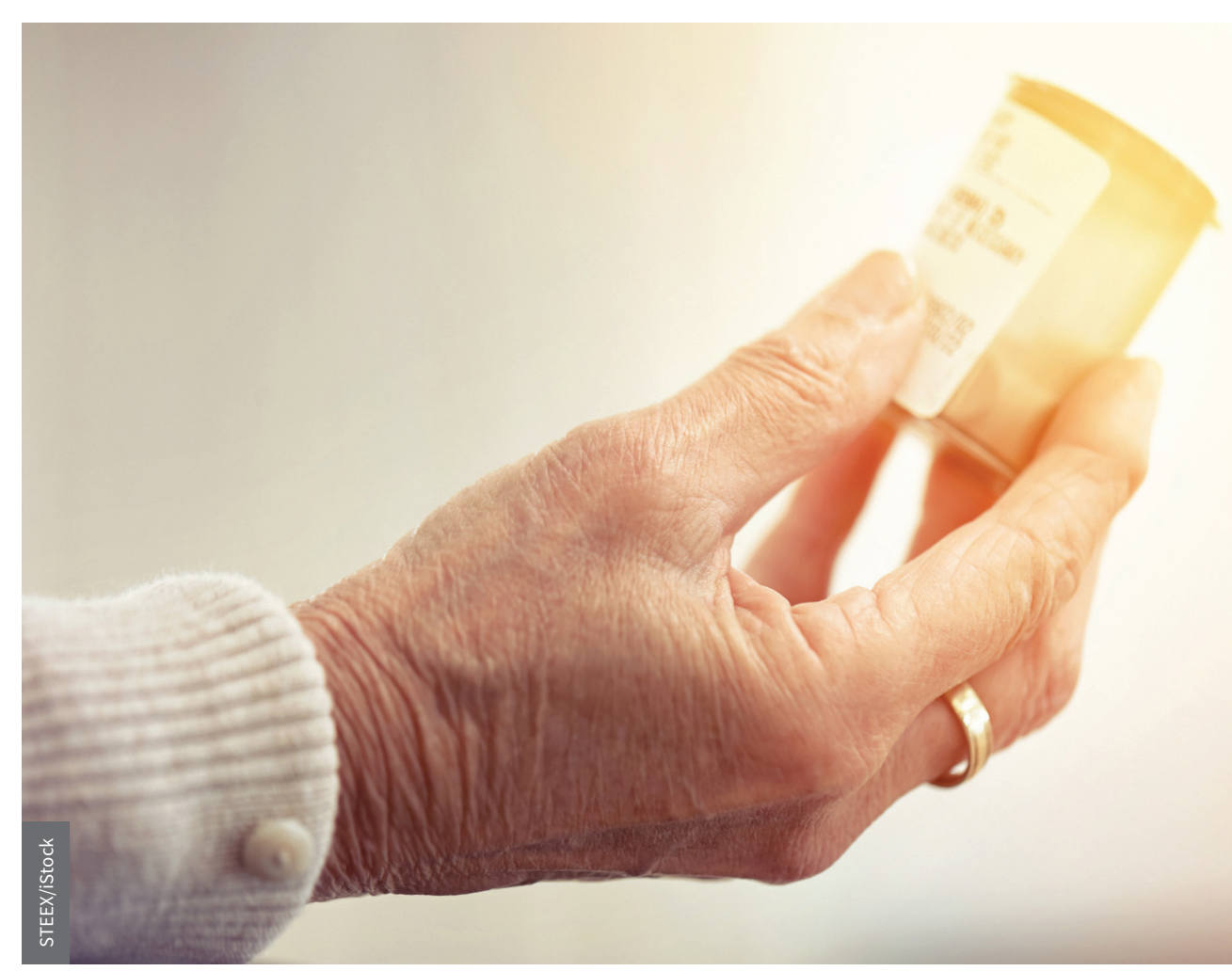

One health equity problem shared by both Canada and the US: the percentage of patients who can't afford to fill their prescriptions. 
"My crystal ball is fairly cracked with this administration," said Dr. Robert Phillips, vice president for research and policy at the American Board of Family Medicine. He pointed out that research by the National Institutes of Health has long enjoyed strong support from both parties in Washington. Other centres, though, may be at more risk.

The Center for Medicare \& Medicaid Innovation, part of the Health and Human Services Department (HHS), is one big question mark. The centre is charged with finding new payment models for a range of common procedures and lowering their cost to government. Its results matter to both countries as they seek to scale up integrated care. The new HHS secretary, Dr. Tom Price, sharply criticized the centre last year, yet hailed its "great promise" during his Senate confirmation hearings in January, but did not commit to preserving it.

Tamblyn said researchers and policymakers at the symposium were keen to hear about lessons learned in three of the most challenging areas of primary health care: patient-centred care for people with multiple chronic conditions, health inequity across diverse communities and alternative payment models. "We now have stacks of comments and ideas from the delegates at the symposium that will help us shape a binational research agenda to advance transformation in integrated primary health care."

Cal Woodward, Washington, DC 